\title{
Dosimetric parameters predicting contralateral liver hypertrophy after unilobar radioembolization of hepatocellular carcinoma
}

\author{
Xavier Palard ${ }^{1,2}$ • Julien Edeline $e^{2,3,4} \cdot$ Yan Rolland $^{5} \cdot$ Samuel Le Sourd $^{4} \cdot$ Marc Pracht $^{4}$. \\ Sophie Laffont ${ }^{1}$ • Laurence Lenoir ${ }^{1}$ - Karim Boudjema ${ }^{6} \cdot$ Thomas Ugen $^{7}$. \\ Vanessa Brun $^{8}$ • Habiba Mesbah ${ }^{9}$ - Laure-Anne Haumont ${ }^{9}$ - Pascal Loyer ${ }^{3}$. \\ Etienne Garin $^{1,2,3}$ (ID
}

Received: 17 July 2017 / Accepted: 28 September 2017 /Published online: 25 November 2017

(C) The Author(s) 2017. This article is an open access publication

\begin{abstract}
Purpose This study aimed at identifying prior therapy dosimetric parameters using ${ }^{99 \mathrm{~m}} \mathrm{Tc}$-labeled macro-aggregates of albumin (MAA) that are associated with contralateral hepatic hypertrophy occurring after unilobar radioembolization of hepatocellular carcinoma (HCC) performed with ${ }^{90} \mathrm{Y}$-loaded glass microspheres.

Methods The dosimetry data of 73 HCC patients were collected prior to the treatment with ${ }^{90} \mathrm{Y}$-loaded microspheres for unilateral disease. The injected liver dose (ILD), the tumor dose (TD) and healthy injected liver dose (HILD) were calculated based on MAA quantification. Following treatment, the maximal hypertrophy (MHT) of an untreated lobe was calculated.

Results Mean MHT was $35.4 \pm 40.4 \%$. When using continuous variables, the MHT was not correlated with any tested variable, i.e., injected activity, ILD, HILD or TD except with a percentage of future remnant liver (FRL) following the ${ }^{90} \mathrm{Y}$-microspheres injection $(r=-0.56)$. MHT $\geq 10 \%$ was significantly more frequent for patients
\end{abstract}

Xavier Palard and Julien Edeline have contributed equally to this study.

Etienne Garin

e.garin@ rennes.unicancer.fr

1 Department of Nuclear Medicine, Cancer Institute Eugène Marquis, Avenue de la Bataille Flandres-Dunkerque, CS 44229, 35042 Rennes cedex, France

2 University of Rennes 1, 35033 Rennes, France

3 INSERM, INRA, Univ Rennes 1, Univ Bretagne Loire, Nutrition Metabolisms and Cancer (NuMeCan), Rennes, France

4 Department of Medical Oncology, Cancer Institute Eugène Marquis, Avenue de la Bataille Flandres-Dunkerque, CS 44229, 35042 Rennes cedex, France with HILD $\geq 88 \mathrm{~Gy},(52 \%$ of the cases $)$, i.e., in $92.2 \%$ versus $65.7 \%$ for HILD $<88$ Gy $(p=0.032)$. MHT $\geq 10 \%$ was also significantly more frequent for patients with a TD $\geq 205$ Gy and a tumor volume $(\mathrm{VT}) \geq 100 \mathrm{~cm}^{3}$ in patients with initial $\mathrm{FRL}<50 \%$. MHT $\geq 10 \%$ was seen in $83.9 \%$ for patients with either an HILD $\geq 88$ Gy or a TD $\geq 205$ Gy for tumors larger than $100 \mathrm{~cm}^{3}$ ( $85 \%$ of the cases), versus only $54.5 \%$ $(p=0.0265)$ for patients with none of those parameters. MHT $\geq 10 \%$ was also associated with FRL and the ChildPugh score. Using multivariate analysis, the Child-Pugh score $(p<0.0001)$, FRL $(p=0.0023)$ and HILD $(p=0.0029)$ were still significantly associated with MHT $\geq 10 \%$.

Conclusion This study demonstrates for the first time that HILD is significantly associated with liver hypertrophy. There is also an impact of high tumor doses in large lesions in one subgroup of patients. Larger prospective studies evaluating the MAA dosimetric parameters have to be conducted to confirm these promising results. 
Keywords Hepatocellular carcinoma $\cdot$ Radioembolization . Predictive dosimetry $\cdot$ Liver hypertrophy $\cdot{ }^{99 \mathrm{~m}} \mathrm{Tc}$-labeled albumin $\cdot{ }^{90} \mathrm{Y}$-loaded glass microspheres

\section{Introduction}

Radioembolization (RE) using ${ }^{90} \mathrm{Y}$-loaded microspheres is increasingly used in a palliative setting for primary $[1,2]$ and secondary liver diseases [3]. The interest of RE for downstaging has also been described $[2,4,5]$ especially in a recent randomized phase 2 study highlighting the superiority of $\mathrm{RE}$ in comparison with chemoembolization [5] opening new perspectives of surgical ablation for patients with large tumors.

Several retrospective studies have recently shown the capacity of RE to induce, after unilateral treatment, a significant hypertrophy of the opposite lobe [6-13], which is of particular interest in a neoadjuvant setting. Indeed, it is recognized that for patients with underlying liver disease, the hepatic reserve or proportion of the future remnant liver (FRL) following RE should be higher than 40 to $50 \%$ of the initial liver mass to avoid post hepatectomy liver failure [12, 14].

Historically, portal vein embolization (PVE) was used to increase the FRL of patients without cirrhosis (mainly with metastatic disease). RE has the advantage of having a direct therapeutic effect on tumors and has been recently proven to be effective in cirrhotic HCC patients [7, 12, 13]. Therefore, understanding the factors inducing liver hypertrophy after RE and developing RE for hypertrophy purposes is of major interest.

The reported mean of hypertrophy after RE varies from 29 to $45 \%$ depending on the studies and on the evaluation time. It is now recognized that the RE-mediated hypertrophy takes place over several months $[13,15,16]$ and that hypertrophy is still increasing between 9 and 12 months after RE [15]. In patients treated by RE, the factors related to hypertrophy are not well described, especially dosimetric factors have not been evaluated to date except the injected activity [10] or the mean treated liver dose $[12,13,16]$ without any statistically significant link identified.

Due to a minimally embolic effect in comparison with PVE, radio-induced damage and cell death within the treated liver lobe are likely to be the main inducer of the hypertrophy in the contralateral RL after RE. Thus, we hypothesized that RL hypertrophy could be at least in part in relation to the levels of injuries and induction of cell death in the injected healthy liver and/or of the tumor itself possibly in relation to the production of growth factors and cytokines [17-20]. It is mandatory to keep in mind that the threshold doses inducing damages are different in tumor versus healthy liver.

In this context, two dosimetric parameters are particularly interesting to evaluate the injected healthy liver dose (HILD) and the tumor dose especially for large lesions as recent studies have demonstrated the accuracy of MAA-based dosimetry in the prediction of tumor response [21-23] and toxicity [24, 25] for HCC patients.

The goal of this study is to evaluate the ${ }^{99 \mathrm{~m}} \mathrm{Tc}$-labeled MAA dosimetric parameters prior $\mathrm{HCC}$ setective internal radiotherapy that would be associated with elevated contralateral hypertrophy after RE with the objective in the future to define specific dosimetric endpoints predicting liver hypertrophy.

\section{Material and methods}

\section{Population}

This retrospective study includes 73 consecutive unilobar HCC patients (including 94\% of cases with cirrhosis) not candidates for surgery treated with ${ }^{90} \mathrm{Y}$-loaded glass microspheres (TherapSphere ${ }^{\circledR}$, BTG UK LtD). Others selection criteria were: no whole liver injection, $\mathrm{CT}$ available for volume measurement performed less than 2 weeks prior to radioembolisation, MAA SCECT/CT available for dosimetric evaluation, no directed liver therapy (surgery, TACE, RFA) 3 months before RE, and no additional treatment during at least 8 weeks after RE. Written informed consent was obtained from each patient, and the use of $\mathrm{RE}$ was approved by the ethics committee of our institution. The indication for using RE was decided by an HCC multidisciplinary tumor board specialized in liver malignancies, including hepatobiliary surgeons. The patient's characteristics are summarized in Table 1.

\section{Planning and administration of ${ }^{90} \mathrm{Y}-$ loaded glass microspheres}

${ }^{90} \mathrm{Y}$-loaded glass microspheres injection was classically preceded by a treatment simulation consisting of a diagnostic angiography and a liver perfusion scan (with planar and SPECT/CT acquisition) following injection of $185 \mathrm{MBq}$ of ${ }^{99 \mathrm{~m}}$ Tc-labeled MAA into the hepatic artery.

A quantitative MAA uptake analysis using a full SPECT/CT segmentation of tumor and non-tumor liver tissue was performed as previously described allowing the calculation of the injected liver dose (ILD), tumor dose (TD) and healthy injected liver dose (HILD) [22].

Glass microspheres were usually injected first week after calibration, on day 3 , and 1 week after evaluating the dosimetric parameters with ${ }^{99 \mathrm{~m}} \mathrm{Tc}$-labeled MAA. Fifty-two patients received a standard radiation dose of 80-150 Gy to the lobe, and 21 received a treatment intensification either at the lobe level $(n=18)$ as previously described [25] or at the segment level $(n=3)$. For all intensified patients the mean whole liver dose was always $<150 \mathrm{~Gy}$. 


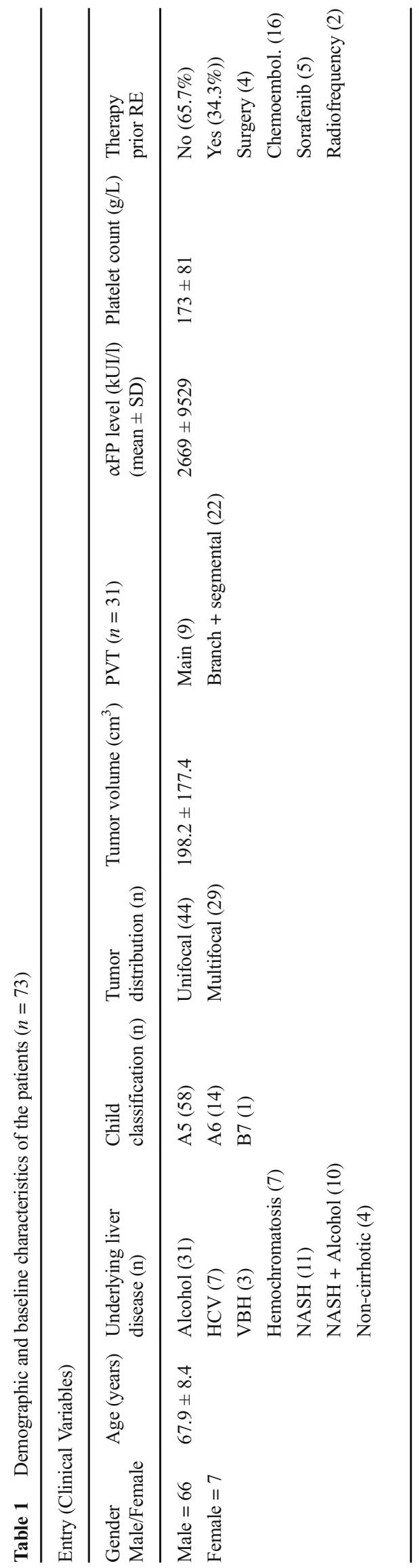

\section{Volumes measurement}

Volume measurements of the whole liver, the injected liver (IL) and the non-injected liver corresponding to the future remnants liver (FLR), were performed before RE, at least between 4 and 8 weeks after RE and then every 12-16 weeks. Volume evaluations were interrupted at the time of progression or surgery. Three periods of volume evaluation were recorded: early (before 2 months), intermediate (between 3 and 5 months) and late (6 months and later). Volumetric assessments were carried out by the Volume Analysis software on a Syngo data-processing console display unit (Siemens) and performed on 5-mm axial slices in the portal phase. The classification of hepatic segments followed the Couinaud segmentation. The delineation was guided by anatomical landmarks and MAA SPECT/CT.

The percentage of hypertrophy (HT\%) is defined as:

$\mathrm{HT} \%=\frac{\text { FLR Volume post RE-FLR Volume previous RE }}{\text { FLR Volume previous RE }} \times 100$

The percentage of atrophy (AT\%) is defined as:

$\mathrm{AT} \%=\frac{\mathrm{IL} \text { Volume previous } \mathrm{RE}-\mathrm{IL} \text { Volume after } \mathrm{RE}}{\mathrm{IL} \text { Volume previous } \mathrm{RE}} \times 100$

Maximal hypertrophy (MHT), maximal atrophy (MAT) and their time of occurrence were recorded for the evaluation.

\section{Outcomes}

Response of treated tumors was assessed using the European Association for the Study of the Liver (EASL) criteria at 3 months. Time to progression (TTP), response rate and disease control rate at 3 and 6 months were recorded.

Toxicities were scored using the common terminology criteria for adverse events (CTCAE) (V4). Serious liver toxicities were defined as permanent and clinically-relevant Grade $\geq$ III liver toxicities, manifesting within 6 months of RE.

\section{Statistical analysis}

Quantitative values were expressed as mean \pm standard deviation (SD). The volumes changes were analyzed using the Wilcoxon paired t test while the MHT was analyzed as a continuous variable and as a dichotomized one, $<10 \%$ or $\geq 10 \%$, as previously described [12]. HT and AT, at the different times of analysis were compared using a paired t-test. Correlation analysis was performed using the Pearson's test. The cut of value of HILD best predicting a MHT $\geq 10 \%$, was defined using ROC analysis.

To evaluate the potential effect of tumor irradiation on hypertrophy, tumors were classified according to their absorbed dose and volume. The threshold tumor dose of $205 \mathrm{~Gy}$ 
Table 2 Treatment parameters and outcomes

\begin{tabular}{ll}
\hline Variables & Values \\
\hline Injected Activity & $2.7 \pm 1.2 \mathrm{GBq}$ \\
Injected liver dose (ILD) & $149.9 \pm 44.4 \mathrm{~Gy}$ \\
Tumor dose (TD) & $304.5 \pm 96.9 \mathrm{~Gy}$ \\
Healthy injected liver dose (HILD) & $90.9 \pm 31.2 \mathrm{~Gy}$ \\
Response Rate & $94.5 \%$ \\
Secondary surgery & 9 cases $(12.3 \%)$ \\
Liver Toxicity* & 4 cases $(5.8 \%)$ \\
\hline
\end{tabular}

*Permanent and clinically-relevant Grade $\geq$ III liver toxicities

described previously was used $[22,23]$ and the threshold volume was set as $100 \mathrm{~cm}^{3}$. We hypothesized that a TD $\geq 205 \mathrm{~Gy}$ for lesions $\geq 100 \mathrm{~cm}^{3}\left(\mathrm{TD}_{\geq 2} 205 \mathrm{~Gy}\right.$ for $\left.\mathrm{TV} \geq 100 \mathrm{~cm}^{3}\right)$ might be predictive of high contralateral hypertrophy levels and that TD $<205$ Gy whatever the tumor size, or a small tumor size $\left(<100 \mathrm{~cm}^{3}\right)$ whatever the TD, $\left(\mathrm{TD}<205 \mathrm{~Gy}\right.$ or TV $\left.<100 \mathrm{~cm}^{3}\right)$, was not predictive of hypertrophy.

Factors associated with a MHT $\geq 10 \%$, were analyzed at univariate analysis using a Chi-squared test and multivariate analysis (for independent significant variables identified at univariate analysis) using a logistic regression test. Finally, factors associated with liver toxicity were analyzed at univariate analysis using a Chi-squared test.

Median TTP was estimated using the Kaplan-Meier method.

SAS software (Version 9.3) was used for the statistical analyses with a significance threshold set at $p \leq 0.05$.

\section{Results}

\section{Variations in liver's volumes evidencing contralateral hypertrophy}

The treatment parameters (injected activity, absorbed doses) and outcomes (response rate, permanent G3 liver toxicity, secondary surgery) are presented in the Table 2.

Livers volumes significantly changed before and after RE, at time of maximal hypertrophy of the untreated liver.

Evolution of liver volumes are presented in the Table 3.

Fifty-eight patients $(79.5 \%)$ had a MHT $\geq 10 \%$ and five patients $(20.5 \%)$ had no or minimal hypertrophy, (i.e.,
MHT < 10\%). The MHT mean was $35.4 \pm 40.4 \%$ and was observed $5.9 \pm 3.4$ months after RE confirming the compensatory hypertrophy in the contralateral untreated liver.

The proportion of patients with a volume of non-injected liver corresponding to the future remnant liver $<50 \%$ prior $\mathrm{RE}$ was $47.9 \%$ and significantly decreased to $13.6 \%$ only at time of MHT $(p<0.0001)$.

The mean of maximal atrophy reached $41.5 \pm 9.8 \%$ of the initial volume and was observed $5.9 \pm 3.1$ months after RE. Only two patients (i.e., 2.7\%) had no or minimal atrophy, i.e., atrophy $<10 \%$.

Evolution of HT and AT regarding the time of evaluation are presented in Fig. 1.

Mean time evaluation was $1.6 \pm 0.4,4.5 \pm 1.1$ and $9.9 \pm 2.6$ months for respectively early (T1), intermediate (T2) and late (T3) time points.

Mean HT significantly increased from $17.5 \pm 13.8 \%$ to $25.7 \pm 28.3 \%$ between $\mathrm{T} 1$ and $\mathrm{T} 2, p=0.0020$ and also significantly increased to $43.3 \pm 56.6 \%$ between $\mathrm{T} 2$ and T3, $p=0.0047$.

Mean AT significantly increased from $15.5 \pm 14.1 \%$ to $34.3 \pm 15.9 \%$ between $\mathrm{T} 1$ and $\mathrm{T} 2, p<0.0001$ and also significantly increased to $56.2 \pm 15.8 \%$ between $\mathrm{T} 2$ and $\mathrm{T} 3$, $p<0.0001$.

\section{Analysis for continuous variables}

MHT mean was correlated only with the initial HR corresponding to the volume of the liver that was not injected during RE ( $r=-0.34, p=0.0031)$ while the MAT was not significantly correlated with any parameters tested (Table 4).

MHT mean was also found significantly higher for Child A patients, $\mathrm{HR}<50 \%$ and patients who received $\mathrm{RE}$ at least as a second line treatment. No statistical difference was observed regarding the PVT status, hypersplenism defined as a platelet count below 100,000 G/l, (but a trend was present), response rate, toxicity, HILD threshold identified with ROC analysis and $\mathrm{TD}\left(\mathrm{TD} \geq 205 \mathrm{~Gy}\right.$ for $\mathrm{TV} \geq 100 \mathrm{~cm}^{3} \mathrm{VS} \mathrm{TD}<205 \mathrm{~Gy}$ or TV $<100 \mathrm{~cm}^{3}$ ) (Table 5).

\section{Analysis for dichotomized variables}

The HILD threshold best predicting a MHT $\geq 10 \%$ identified at ROC analysis was $88 \mathrm{~Gy}$ with a sensitivity of $80.9 \%$ and a specificity of $60.3 \%$ (area under the curve 0.7017 ) Fig. 2.
Table 3 Mean liver volume (cc) and mean evolutions (cc)

\begin{tabular}{lllll}
\hline & Prior injection & At time of MHT & Change & $P$ value \\
\hline Injected volume & $899.6 \pm 311.8$ & $540.2 \pm 257.7$ & Decrease of 359. \pm 236.2 & $<0.0001$ \\
FRL & $868.6 \pm 354.1$ & $1113.4 \pm 425,3$ & Increase of $244.6 \pm 208.9$ & $<0.0001$ \\
Whole liver & $1748.2 \pm 424.2$ & $1662.1 \pm 444.4$ & Decrease of $87.6 \pm 274.6$ & 0.0084 \\
FRL $(\%)$ & $49.7 \pm 15.9$ & $66.7 \pm 15.6$ & Increase of $17.0 \pm 11.7$ & $<0.0001$ \\
\hline
\end{tabular}


Fig. 1 Evolution of hypertrophy (HT) of the FLR and atrophy of the treated liver (AT) regarding time

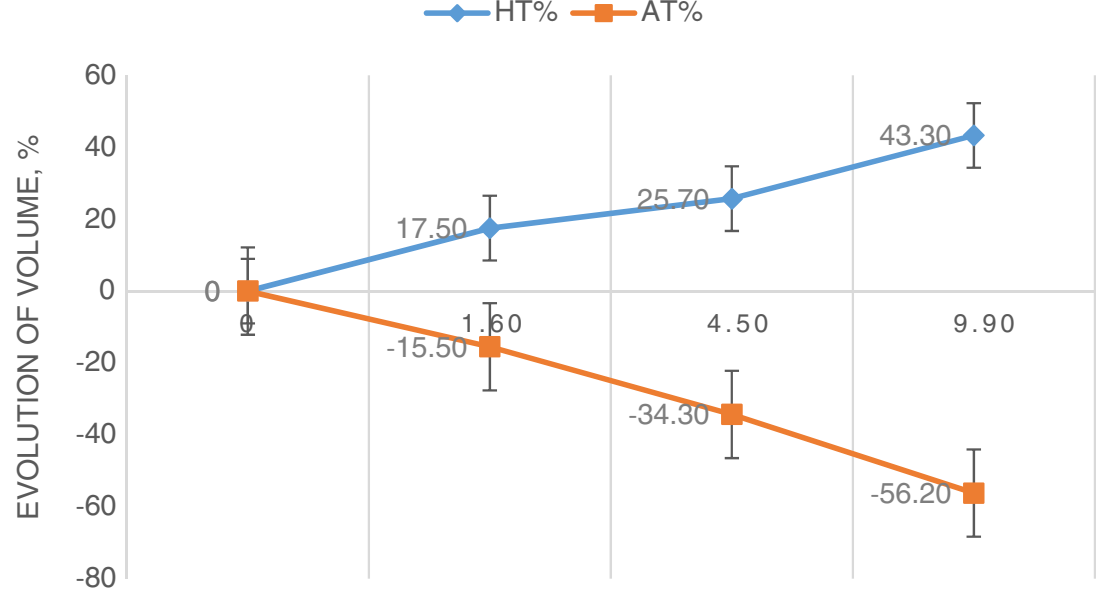

TIME, MONTHS
Using univariate analysis, the MHT $\geq 10 \%$ was significantly associated with HILD ( $<$ or $\geq 88$ Gy) example see Fig. 3, HR ( $<$ or $\geq 50 \%)$ and Child-Pugh score (A5 versus A6 + B7), the combined variable HILD $\geq 88$ Gy and/or $\mathrm{TD}_{\geq 2}$ 205Gy for $\mathrm{TV} \geq 100 \mathrm{~cm}^{3}$ (present in $85 \%$ of the cases) but not with PVT status, hypersplenism, response ratio, toxicity, treatment line, and $\mathrm{TD}\left(\mathrm{TD}_{\geq 2} 205 \mathrm{~Gy}\right.$ and $\mathrm{TV} \geq 100 \mathrm{~cm}^{3}$ vs $\mathrm{TD}<205 \mathrm{~Gy}$ or $\mathrm{TV}_{<}$ $100 \mathrm{~cm}^{3}$ ) (Table 6). Moreover, with a multivariate analysis, the status of HILD, HR and Child status was still significantly linked with a MHT $\geq 10 \%$ (Table 6).

\section{Subgroup analysis according to FLR and HILD}

FLR $<50 \%$ was seen in $47.9 \%$ of the cases at baseline. For patients with a FLR $<50 \%$, MHT mean was significantly higher for $\mathrm{TD} \geq 205 \mathrm{~Gy}$ for $\mathrm{TV}_{\geq 100 \mathrm{~cm}}{ }^{3}$ compared to the cases with a $\mathrm{TD}_{<205 \mathrm{~Gy}}$ or $\mathrm{TV}_{<100 \mathrm{~cm}}$, with $62.3 \pm 62.3 \%$ versus only $29.1 \pm 25.6 \%$, respectively ( $p=0.0329$ ), for example, see Fig. 4. In this group of patients, the HTM was not significantly higher for patients with HILD $\geq 88$ Gy than for cases with HILD $<88$ Gy with means of $52.5 \pm 64.4 \%$ versus $42.2 \pm 29.7 \%$, respectively. For patients with a FLR $\geq 50 \%$, MHT was significantly higher for cases with HILD $\geq 88$ Gy than for cases with HILD $<88$ Gy with means of $27.6 \pm 19.9 \%$ versus $17.9 \pm 18.8 \%(p=0.0454)$, respectively. In this group of patients, the HTM was not significantly higher for TD $\geq$ 205Gy for $\mathrm{TV}_{\geq 100 \mathrm{~cm}}{ }^{3}$ compared to that of patients with a $\mathrm{TD}_{<}$ $205 \mathrm{~Gy}$ or a $\mathrm{TV}_{<100 \mathrm{~cm}^{3}}$ with means of $25.7 \pm 24.3 \%$ versus $24.6 \pm 17.6 \%$, respectively.

HILD $<88$ Gy was seen in $47.9 \%$ of the cases. In this group of patients, there was a trend towards a MHT mean higher for patients with $\mathrm{TD} \geq 205 \mathrm{~Gy}$ for $\mathrm{TV}_{\geq 100 \mathrm{~cm}^{3}}$, i.e., $43.9 \pm 59.6 \%$ in comparison with patients with $\mathrm{TD}<205 \mathrm{~Gy}$ or $\mathrm{TV}_{<100 \mathrm{~cm}}{ }^{3}$, i.e., $24.1 \pm 59.6 \%$, but it was not statistically significant. Indeed, the MHT $\geq 10 \%$ was seen for $70.8 \%$ of the patients with a TD $\geq 205 \mathrm{~Gy}$ for $\mathrm{TV}_{\geq 100 \mathrm{~cm}}{ }^{3}$ compared to a mean of only $54.5 \%$ when $\mathrm{TD}_{<205 \mathrm{~Gy}}$ or $\mathrm{TV}_{<100 \mathrm{~cm}^{3}}(\mathrm{~ns})$.

\section{Response, TTP and disease control rate (DCR)}

Response rate was $94.5 \%$.

At time of analysis, $79.4 \%$ of the patients had recurrence. Median TTP was 11.0 months (CI 95\%: 8.5-14.0 months).

Recurrence was in the non-treated liver for $50.7 \%$ of the treated patients and in the treated liver for $28.8 \%$ of the patients.

DCR was $98.6 \% 3$ months after RE (only one progression) and $71.2 \%$ at 6 months, with a progression in the treated liver for only $10.9 \%$ of the patients and in the non-treated liver for $17.8 \%$ of the patients.

\section{Toxicity analysis}

HILD mean was $91.1 \pm 31.9$ Gy for patients without serious liver toxicity and $89.3 \pm 11.5$ Gy for patients with liver toxicity $(n=4)$, without statistical significance (ns). In contrast, toxicity was significantly associated with hypersplenism

Table 4 Correlation coefficients (r) and their $p$ value for MHT\% and MAT\% regarding tested variables

\begin{tabular}{|c|c|c|c|c|}
\hline \multirow[t]{2}{*}{ Variables } & \multicolumn{2}{|l|}{ MHT } & \multicolumn{2}{|c|}{ MAT } \\
\hline & $\mathrm{r}$ & $p$ value & $\mathrm{r}$ & $p$ value \\
\hline Injected activity (GBq) & 0.18 & ns & 0.11 & ns \\
\hline ILD (Gy) & 0.09 & ns & 0.05 & ns \\
\hline TD (Gy) & 0.07 & ns & 0.05 & $\mathrm{~ns}$ \\
\hline $\mathrm{TV}(\mathrm{cc})$ & 0.01 & $\mathrm{~ns}$ & 0.07 & $\mathrm{~ns}$ \\
\hline HILD (Gy) & 0.10 & $\mathrm{~ns}$ & 0.20 & $\mathrm{~ns}$ \\
\hline $\operatorname{HR}(\%)$ & -0.34 & 0.0031 & 0.01 & $\mathrm{~ns}$ \\
\hline Platelet count (G/l) & 0.04 & $\mathrm{~ns}$ & 0.10 & ns \\
\hline MAT (\%) & 0.22 & ns & & ns \\
\hline
\end{tabular}

MHT, maximal hypertrophy; MAT, maximal atrophy 
Table 5 Comparison of means of MHT\% (continuous variable) according to tested variables

\begin{tabular}{|c|c|c|}
\hline Variables & Means MHT $(\%)$ & $P$ value \\
\hline Child A5 vs Child A6 + B7 & $40.1 \pm 42.5$ vs $17.4 \pm 23.8$ & 0.0017 \\
\hline $\mathrm{HR}<50 \%$ vs $\geq 50 \%$ & $48.1 \pm 52.0$ vs $23.8 \pm 19.8$ & 0.0092 \\
\hline First line vs $\geq$ second line & $26.83 \pm 23.7$ vs $51.9 \pm 57.8$ & 0.0085 \\
\hline Hyperslenism present vs absent & $19.5 \pm 18.7$ vs $39.2 \pm 43.2$ & $\begin{array}{l}\text { ns, but trends } \\
\quad(p=0.06)\end{array}$ \\
\hline PVT present vs absent & $39.5 \pm 52.4$ vs $32.1 \pm 27.1$ & ns \\
\hline Response vs no response & $36.4 \pm 40.8$ vs $12.4 \pm 17.1$ & ns \\
\hline Liver toxicity vs no liver toxicity & $29.8 \pm 33.2$ vs $35.7 \pm 40.9$ & ns \\
\hline HILD $<88$ Gy vs $\geq 88$ Gy & $33.3 \pm 24.9$ vs $37.7 \pm 52.6$ & ns \\
\hline $\begin{array}{l}\text { HILD } \geq 88 \mathrm{~Gy} \text { or } \mathrm{TD}_{\geq 205 \mathrm{~Gy}} \text { for } \mathrm{TV} \geq 100 \mathrm{~cm} \\
\text { vs } \mathrm{HILD}<88 \mathrm{~Gy} \text { and } \mathrm{TD}<205 \mathrm{~Gy} \text { or } \mathrm{TV}<100 \mathrm{~cm}^{3}\end{array}$ & $37.4 \pm 41.7$ vs $24.3 \pm 30.3$ & ns \\
\hline $\begin{array}{l}\mathrm{TD}_{\geq 205 \mathrm{~Gy} \text { for } \mathrm{TV}} \geq 100 \mathrm{~cm}^{3} \mathrm{vs} \mathrm{TD}<205 \mathrm{~Gy} \\
\text { or } \mathrm{TV}<100 \mathrm{~cm}^{3}\end{array}$ & $40.7 \pm 47.5$ vs $27.4 \pm 24.6$ & ns \\
\hline
\end{tabular}

$(p=0.0224)$ but not with HILD ( $<$ or $\geq 88$ Gy), FLR $(<$ or $\geq 50 \%$ ) and Child status (A5 vs A6 + B7).

\section{Discussion}

In this report, we have measured the dosimetric parameters following unilobar injection of ${ }^{99 \mathrm{~m}} \mathrm{Tc}$-labeled MAA in patients suffering from $\mathrm{HCC}$ and prior ${ }^{90} \mathrm{Y}$-loaded microspheres radiotherapy in order to define specific dosimetry endpoints associated with elevated contralateral hypertrophy in noninjected liver after RE.

The first main result of this study is the clear impact of the HILD on the occurrence of a MHT $\geq 10 \%$ identified both at univariate $(p=0.0081)$ and multivariate analysis $(p=0.0029)$. MHT $\geq 10 \%$ was observed in $92.2 \%$ of the patients having a HILD $\geq 88 \mathrm{~Gy}$, (representing $52 \%$ of the population), while the MHT $\geq 10 \%$ was found in only $65.7 \%$ of the patients when HILD was $<88$ Gy. To the best of our knowledge, this is the first demonstration that a dosimetric parameter positively correlates with hypertrophy. Indeed, previous studies have failed to find any correlation between dosimetric parameters and hypertrophy. However, in these reports, the dosimetric evaluation relied on the dose to the treated liver [12, 13], which is not the best dosimetric parameter to evaluate since it is a mean dose between TD and HILD. This has also been the case in the study previously reported by Fernandez-Ros et al. [18] who have evaluated the HILD using the partition model; however, it seems that in this study HILD was only evaluated as a continuous variable. The fact that radio-induced damage is determinist and responds to a threshold can explain the absence of a link between HILD and hypertrophy in the study published by Fernandez-Ros and colleagues [18].

One way to significantly enhance hypertrophy seems to be to deliver HILD higher than 88 Gy. However, the maximal deliverable HILD without inducing liver failure is not well described. Chiesa et al. [24] found a mean healthy liver dose (mean dose to the injected and not injected healthy liver) of 75 Gy producing a probability of G2 liver toxicity of $15 \%$. In a previous study of 71 cases, we found no link between HILD and liver toxicity but only a significant link for HILD > 100 Gy and a low hepatic reserve $(<30 \%)$ [25]. In the present study, no significant link was found between liver G3 permanent toxicity and HILD ( $<88$ versus $\geq 88 \mathrm{~Gy}$ ). However, the maximal HILD to deliver to induce the optimal hypertrophy in case of low initial RL should be evaluated prospectively.

For the patients with a low HILD ( $<88$ Gy, i.e., $48 \%$ of the cases), other dosimetric parameters than HILD, such as TD for large lesions, could have an impact on hypertrophy. In this situation $\mathrm{MHT} \geq 10 \%$ was present in $70.8 \%$ of the patients with a high dose to large tumors $\left(\mathrm{TD}_{\geq 205 \mathrm{~Gy} \text { for } \mathrm{TV} \geq 100 \mathrm{~cm}}{ }^{3}\right.$ ) as against

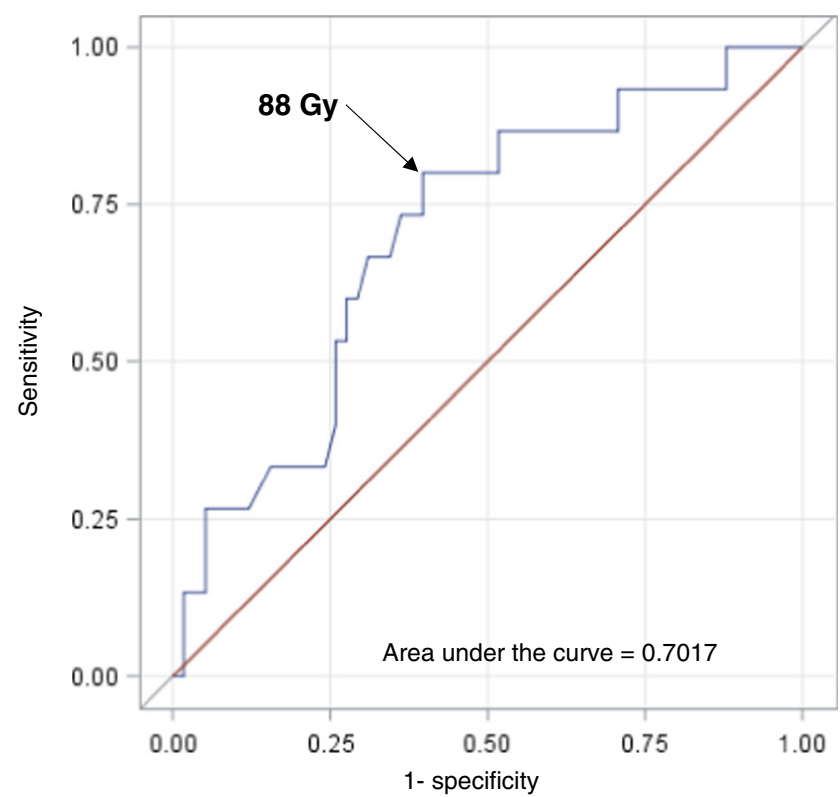

Fig. 2 ROC curves analysis for the identification of the HIL threshold dose predicting a $\mathrm{MHT} \geq 10 \%$ 

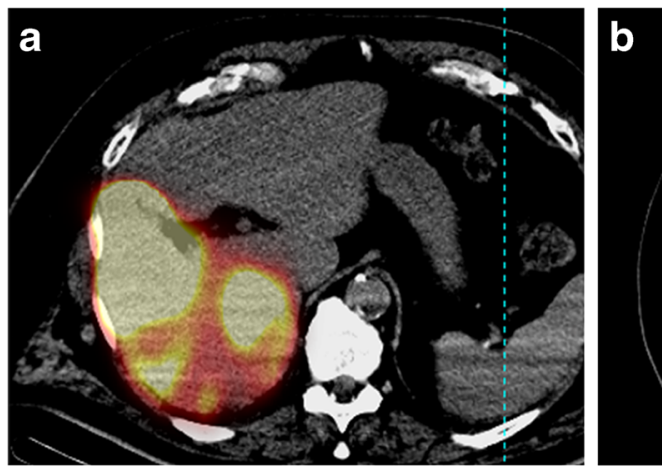

Fig. 3 Example of hypertrophy related to a high HILD. This 74-year-old man with a Child A5 cirrhosis was treated with $2.2 \mathrm{GBq}$ of ${ }^{90} \mathrm{Y}$-loaded glass microspheres injected in the RHA for HCC recurrences in the right lobe after chemoembolization. ILD was $121 \mathrm{~Gy}$, HILD 114 Gy, and TD 346 Gy for a tumoral volume of $43 \mathrm{~cm}^{3}$. The MAA scintigraphy showed

only in $54.4 \%$ for low tumor dose $(<205$ Gy) or small tumor volume $\left(<100 \mathrm{~cm}^{3}\right)$. This result was not statistically significant, but this trend highlights the potential impact of high tumor dose for large lesions on MHT. However, in one subgroup analysis (the subgroup of patients with a $\mathrm{HR}<50 \%$ ) the parameter $\mathrm{TD}_{\geq}$ $205 \mathrm{~Gy}$ for $\mathrm{TV} \geq 100 \mathrm{~cm}^{3}$ significantly impacted the contralateral hypertrophy. In fact, in this subgroup of patients, the MHT mean was significantly higher in cases of $\mathrm{TD} \geq 205 \mathrm{~Gy}$ for $\mathrm{TV} \geq 100 \mathrm{~cm}^{3}(62.3 \pm 53.3 \%)$ versus only $29.1 \pm 25.6 \%$ in cases with a TD $<205$ Gy or a TV $<100 \mathrm{~cm}^{3},(p=0.0329)$. This group of patients is of particular importance, as it represents the population that most needed the hypertrophy to be induced by RE.

It is interesting to underline that, for the same injected liver dose the lower the HILD is, the larger usually the tumors are with high doses due to the partitioning of the activity between the healthy liver and tumor. So for patients with low HILD, it seems possible to safely increase the dose in cases of large

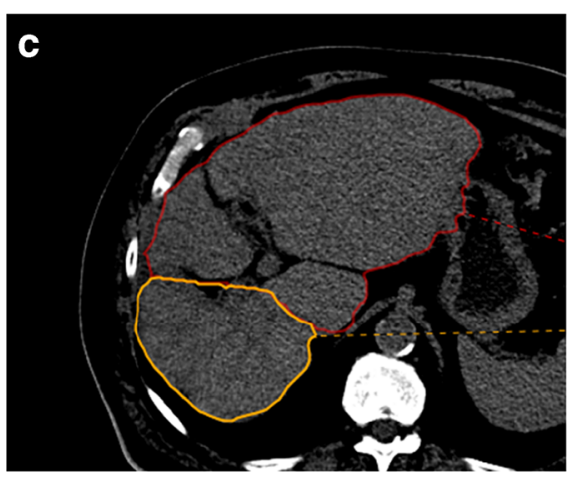

an absence of perfusion of the segment 1 (a). The initial hepatic reserve was $52 \%$ (b). At 9 months, a hypertrophy of $66 \%$ of the left lobe (+ segment 1) was found and a 54\% atrophy of the treated right lobe (excluding segment 1) was observed (C). The hepatic reserve after RE was $79.9 \%$

tumors, to obtain $\mathrm{TD} \geq 205 \mathrm{~Gy}$, in order to stimulate hypertrophy, without reaching too high a HILD.

Finally, MHT $\geq 10 \%$ was seen in $83.9 \%$ for patients with $\mathrm{HILD} \geq 88$ Gy or a $\mathrm{TD}_{\geq 205 \mathrm{~Gy}}$ for $\mathrm{TV} \geq 100 \mathrm{~cm}^{3}$, representing $85 \%$ of the population, while MHT $\geq 10 \%$ was found only in $54.5 \%(p=0.0265)$ for patients with none of those parameters $(p=0.0265)$.

Thus, our results are suggesting that optimizing and increasing either the HILD or the TD for large lesions could result in producing significantly higher hypertrophy for at least $85 \%$ of the patients. This data should be taken into account when discussing RE in the neoadjuvant setting of HCC. One issue not evaluated in this study is the potential impact of increasing the number of microspheres used instead of the doses. Other studies are warranted to evaluate the potential impact of microspheres number (i.e., the embolic load) on hypertrophy after RE.
Table 6 Univariate and multivariate analysis of factors potentially associated with MHT $\geq 10 \%$

\begin{tabular}{|c|c|c|c|}
\hline Variables & $\begin{array}{l}\text { Frequency of } \\
\text { MHT } \geq 10 \%\end{array}$ & $\begin{array}{l}\text { Univariate } \\
\text { analysis }\end{array}$ & $\begin{array}{l}\text { Multivariate } \\
\text { analysis }\end{array}$ \\
\hline FLR $<50 \%$ vs $>50 \%$ & 92.4 vs $68.4 \%$ & $p=0.0203$ & $p=0.0023$ \\
\hline HILD $<88$ Gy vs $\geq 88 \mathrm{~Gy}$ & $65.7 \%$ vs 92.2 & $p=0.0081$ & $p=0.0029$ \\
\hline $\begin{array}{l}\mathrm{TD}_{\geq 205 \mathrm{~Gy} \text { and } \mathrm{TV}} \geq 100 \mathrm{~cm}^{3} \text { vs TD }<205 \mathrm{~Gy} \\
\text { or } \mathrm{TV}<100 \mathrm{~cm}^{3}\end{array}$ & 81.8 vs $75.8 \%$ & ns & - \\
\hline $\begin{array}{l}\text { HILD } \geq 88 \text { Gy or TD } \geq 205 \text { Gy for } \mathrm{TV} \geq 100 \mathrm{~cm}^{3} \mathrm{vs} \\
\text { HILD }<88 \text { Gy and } \mathrm{TD}<205 \text { Gy } \text { or } \mathrm{TV}<100 \mathrm{~cm}^{3}\end{array}$ & 83.9 vs $54.5 \%$ & $p=0.0265$ & not tested* \\
\hline Child A5 vs A6 + B7 & 89.6 vs $40.0 \%$ & $p=0.0001$ & $p<0.0001$ \\
\hline PVT present vs absent & 81.8 vs $78.9 \%$ & ns & - \\
\hline Hypersplenism present vs absent & 71.4 vs $80.7 \%$ & ns & - \\
\hline Response vs no response & 81.4 vs $33.3 \%$ & ns & - \\
\hline Liver toxicity vs no liver toxicity & 75.0 vs $79.7 \%$ & ns & - \\
\hline First line vs $\geq$ second line & 72.9 vs $92.9 \%$ & $\begin{array}{l}\text { ns, but trends } \\
\quad(p=0.0706)\end{array}$ & - \\
\hline
\end{tabular}

The mixed variable HILD $\geq 88$ Gy or $\mathrm{TD} \geq 205 \mathrm{~Gy}$ for $\mathrm{TV} \geq 100 \mathrm{~cm}^{3}$ was not tested in multivariate analysis as this variable depends on the variables HILD $\geq 88$ Gy and TD $\geq 205$ Gy for TV $\geq 100 \mathrm{~cm}^{3}$ 

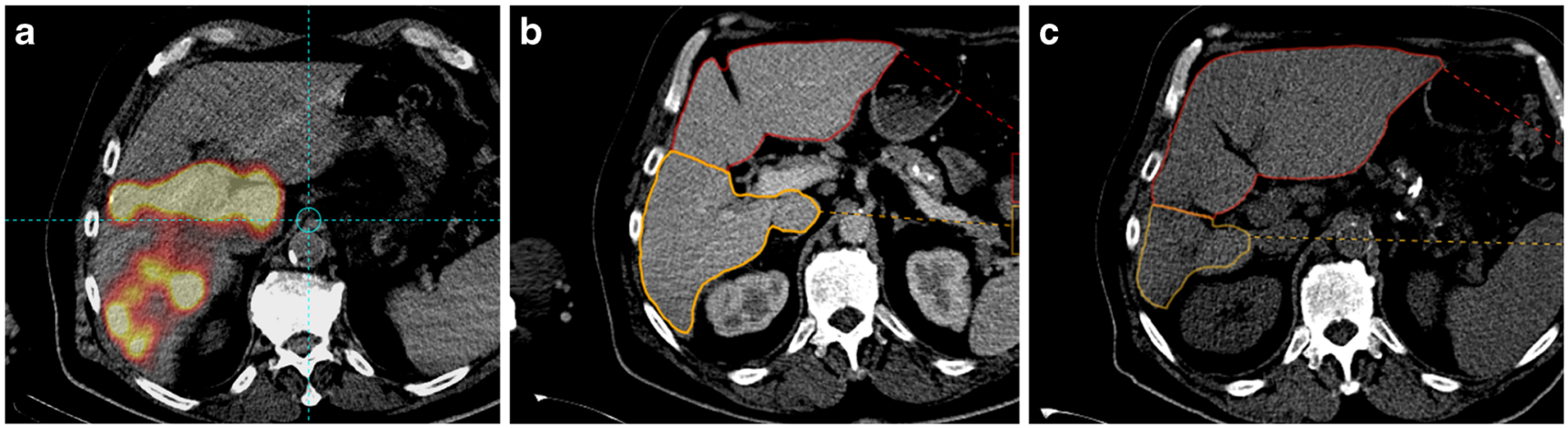

Fig. 4 Example of hypertrophy related to a high TD for a large tumor for a patient with a very low HILD. This 66-year-old man with a Child A6 cirrhosis with a large unifocal HCC recurrence after chemoembolization was treated with $1.5 \mathrm{GBq}$ of ${ }^{90} \mathrm{Y}$-loaded glass microspheres injected in the RHA. The ILD was 130 Gy, HILD was 21 Gy only while TD was

After loss of the hepatic mass, the liver/body weight ratio returns to $100 \%$ because of the ability of the liver to regenerate. This process, also called Hepatostat [26, 27], allows the adjustment of its size to the overall body metabolic requirement. Using both in vitro and in vivo rodent models, it has been shown that the unique ability of differentiated hepatocytes to exit from quiescence and to proliferate is controlled by a plethora of cytokines and growth factors. The proinflammatory cytokines tumor necrosis factor $\alpha$ (TNF $\alpha)$ and interleukin 6 (IL-6) are the early stimuli during the liver regeneration allowing the priming of hepatocytes, whereas growth factors such as HGF, TGF $\alpha$ and EGF regulate the onset of DNA synthesis [28-30]. Many other soluble factors such as the vascular endothelial growth factor (VEGF), platelet derived growth factor (PDGF), and Augmenter of Liver Regeneration (ALR) strongly potentiate the effects of the pro-inflammatory cytokines and growth factors to achieve a complete liver regeneration and to rescue any partial defect in the secretion of one or another factor.

While the molecular mechanisms triggering the liver regeneration after partial hepatectomy have been extensively studied in rodents, the growth factors and downstream pathways regulating proliferation of hepatic cells in humans during chronic liver diseases are not well understood. In diseased human liver, the chronic loss of mature hepatocytes is not compensated by an efficient proliferation leading to the development of cirrhosis, the alterations of the liver macrophage phenotype, the abnormal production of cytokines and the appearance of progenitor cells [27]. In this pathological context, the surgical resection or the RE of HCC induce a more or less efficient liver regeneration of the non-tumoral liver although the humoral mediators remain poorly described.

However, a production of several cytokines and growth factors including VEGF, bFGF, PDGF, IL6 and HF has been recently demonstrated after RE that may constitute possible prognostic factors for the overall survival outcome [17-20].
361 Gy for a tumoral volume of $151 \mathrm{CC}$. The MAA scintigraphy confirmed a perfusion of segment 1 (a). The initial hepatic reserve was $39 \%$ (b). At 6.5 months after RE, we observed a hypertrophy of $82 \%$ of the left lobe and a $52 \%$ atrophy of the right treated lobe. The hepatic reserve was then $71 \%(\mathrm{C})$

To date, the mechanisms that trigger this production and the cell types secreting these mediators during RE are not known.

Individualizing two targets, the healthy treated liver and the tumor itself, as done in this study, seems logical in case of RE, which is responsible of tumor necrosis and can lead to injuries in the healthy liver [31]. Then, several hypothesis concerning the biological mechanisms that trigger the liver hypertrophy can be proposed. Since RE is recognized to be minimally embolic, a portal flow redistribution from the treated liver to the RL or shear-stress that could induce hypertrophy after PVE [32] is unlikely to be the main initial event with RE, even though RE is known to produce variable signs of portal hypertension with time [8,9].

A reduction of the functional mass of the treated liver, supposedly correlated with the HILD, can be a valuable hypothesis since a significant atrophy of the treated liver is described in all RE studies [6-13]. This is the rationale for the concept of radiation lobectomy used by several authors $[7,13$, 19]. In this situation, the treated lobe atrophy has been proven to be larger than the tumoral volume, confirming an atrophy of the healthy injected liver. The significant link between a HILD $\geq 88$ Gy and the frequency of HTM $\geq 10 \%$ found in the present study supports this hypothesis. The good tolerance of radiation lobectomy reported in all studies [6-13] in case of insufficient FLR, in comparison with surgical lobectomy, which is an immediate ablative approach, is certainly in relation to the fact that maximal atrophy is time dependent and takes several months to occur $[13,15,16]$. Therefore, the atrophy taking place after RE is certainly compensated by the occurrence of liver regeneration in the FRL in the meantime.

A second possible mechanism is the direct antitumoral effect of RE, not seen with PVE, with the potential release of mediators in case of tumor stress and necrosis (supposed to be in relation with the TD). The amount of the released mediators certainly depends upon the tumor volume and the TD. 
Elsewhere, HCCs are recognized to be potentially functional and, in this situation, the destruction of HCCs can lead to a reduction of the functional mass of the liver. This hypothesis is supported by the trends and significant link in one subgroup between a TD $\geq 205 \mathrm{~Gy}$ for $\mathrm{TV} \geq 100 \mathrm{~cm}^{3}$ and the frequency of $\mathrm{HTM} \geq 10 \%$ shown in our study.

Regarding global results of hypertrophy, the MHT mean reported herein after RE, i.e., $35.4 \pm 40.4 \%$, are in agreement with previously reported data, i.e., mean (or median) MTH ranking from 29 to $45 \%$ depending on the studies and on the evaluation time $[13,15,16]$.

It is now clearly established that RE significantly reduces the amount of patients with inaccurate FLR. Indeed, it has been demonstrated in previous studies that the proportion of patients with a too small FLR significantly decreased after RE. A FLR $<50 \%$ decreased from $52.9 \%$ to $32.4 \%, p=0.013$, after RE in a previous study, $p=0.013$ [12] and a FLR $<40 \%$ also significantly decreased from $56.6 \%$ to $29.4 \%$ after RE in the study published by Fernadez-Ros et al., $p<0.001$ [16]. Similarly in our study, the proportion of patients with a FLR $<50 \%$ prior RE, significantly decreased from $47.9 \%$ to $13.6 \%$ only at time of MHT $(p<0.0001)$.

Thus one subsequent key question is "how long we could wait for hypertrophy occurrence after RE" as it is also recognized that in this situation hypertrophy takes more time to occur than with PVE. In our study DCR was $98.6 \%$ at 3 months underlying the absence of significant risk of progression within 3 months after RE. However, DCR reduced to $71.2 \%$ at 6 months (but with progression in the treated liver in only $10.9 \%$ of the patients and in the non-treated liver for $17.8 \%$ of the patients).

So, we can recommend to wait at least 3 months after RE to evaluate hypertrophy and to check for patients operability. At 3 months, if hypertrophy is not sufficient enough, later evaluations can be recommended, especially at 6 months, as hypertrophy can take more than 3 months to occur, but in this situation a significant amount of patients will no more be candidates for surgery due to tumor progression in the non treated liver (17.8\% in our experience).

Those data are confirming the interest in RE to produce significant liver hypertrophy, even in patients with underlying cirrhosis, while producing in the same way an accurate tumor control, which is not achievable while using PVE.

The main limitations of this study are its retrospective nature and the number of patients included. Despite a relative large number of patients (i.e., 73) in comparison with previously published studies $[13,16]$ of post RE hypertrophy in HCC (52 and 67 HCC patients in the two largest previous cohorts) subgroup analysis power is certainly not sufficient since the number of subgroup cells was below ten for the several analysis.

Elsewhere in the evaluation of the FRL after RE, the volume of the treated liver is considered as functional as the FRL itself, which is certainly not the case. Then, a simple volumetric analysis, in this situation of RE, more than likely underestimates the real percentage of the function of the FLR. In fact, an important reduction of the liver function of the treated lobe has been recently described using hepatobiliary scintigraphy in two patients out of three treated by RE [33]. In the future, the use of hepatobiliary scintigraphy should be used to evaluate more accurately the hypertrophy post RE with a more functional approach than a volumetric approach alone.

\section{Conclusion}

This study demonstrates for the first time that HILD $(<$ or $\geq 88 \mathrm{~Gy}$ ) is significantly associated with liver hypertrophy (MHT $\geq 10 \%$ ) with univariate and multivariate analysis underlying the robustness of this parameter. There is also a trend of the impact of high tumor dose in large lesions $\left(\mathrm{TD}_{\geq 2} 205 \mathrm{~Gy}\right.$ for $\mathrm{TV} \geq 100 \mathrm{~cm}^{3}$ ) on MHT with a significant impact in one subgroup analysis. Larger prospective studies evaluating MAA dosimetric parameters have to be designed to confirm those results with the aim to finally define safe specific dosimetric endpoints favoring hypertrophy occurrence.

Acknowledgments The authors thank the Labex IRON for its financial support.

\section{Compliance with ethical standards}

Conflict of interest Disclosure of potential conflicts of interest: Julien Edeline, Yan Rolland and Etienne Garin are advisors to BTG UK Ltd.

No other conflicts exist.

Ethical approval All applicable national and institutional guidelines for human studies were followed. The use of RE was approved by the ethics committee of our institution and written informed consent was obtained from each patient.

Open Access This article is distributed under the terms of the Creative Commons Attribution 4.0 International License (http:// creativecommons.org/licenses/by/4.0/), which permits unrestricted use, distribution, and reproduction in any medium, provided you give appropriate credit to the original author(s) and the source, provide a link to the Creative Commons license, and indicate if changes were made.

\section{References}

1. Salem R, Lewandowski RJ, Mulcahy MF, Riaz A, Ryu RK, Ibrahim $\mathrm{S}$, et al. Radioembolization for hepatocellular carcinoma using Yttrium-90 microspheres: a comprehensive report of longterm outcomes. Gastroenterology. 2010;1:52-64.

2. Edeline J, Du FL, Rayar M, Rolland Y, Beuzit L, Boudjema K, et al. Glass Microspheres 90Y Selective Internal Radiation Therapy and Chemotherapy as First-Line Treatment of Intrahepatic Cholangiocarcinoma. Clin Nucl Med. 2015;11:851-5. 
3. van Hazel GA, Heinemann V, Sharma NK, Findlay MP, Ricke J, Peeters M, et al. SIRFLOX: Randomized Phase III Trial Comparing First-Line mFOLFOX6 (Plus or Minus Bevacizumab) Versus mFOLFOX6 (Plus or Minus Bevacizumab) Plus Selective Internal Radiation Therapy in Patients With Metastatic Colorectal Cancer. J Clin Oncol. 2016;15:1723-31.

4. Iñarrairaegui M, Pardo F, Bilbao JI, Rotellar F, Benito A, D'Avola $\mathrm{D}$, et al. Response to radioembolization with yttrium-90 resin microspheres may allow surgical treatment with curative intent and prolonged survival in previously unresectable hepatocellular carcinoma. Eur J Surg Oncol. 2012;7:594-601.

5. Salem R, Gordon AC, Mouli S, Hickey R, Kallini J, Gabr A, et al. Y90 Radioembolization Significantly Prolongs Time to Progression Compared With Chemoembolization in Patients With Hepatocellular Carcinoma. Gastroenterology. 2016;6:1155-63.

6. Rayar M, Sulpice L, Edeline J, Garin E, Levi Sandri GB, Meunier B, et al. Intra-arterial Yttrium-90 Radioembolization Combined with Systemic Chemotherapy is a Promising Method for Downstaging Unresectable Huge Intrahepatic Cholangiocarcinoma to Surgical Treatment. Ann Surg Oncol. 2015;11:851-5.

7. Gaba RC, Lewandowski RJ, Kulik LM, Riaz A, Ibrahim SM, Mulcahy MF, et al. Radiation lobectomy: preliminary findings of hepatic volumetric response to lobar yttrium-90 radioembolization. Ann Surg Oncol. 2009;6:1587-96.

8. Jakobs TF, Saleem S, Atassi B, Reda E, Lewandowski RJ, Yaghmai V. al. Fibrosis, portal hypertension, and hepatic volume changes induced by intra-arterial radiotherapy with $90 \mathrm{yttrium}$ microspheres. Dig Dis Sci. 2008;53(9):2556-63.

9. Teo JY, Goh BK, Cheah FK, Allen JC, Lo RH, Ng DC, et al. Underlying liver disease influences volumetric changes in the spared hemiliver after selective internal radiation therapy with 90 Y in patients with hepatocellular carcinoma. J Dig Dis. 2014;8: 444-50.

10. Ahmadzadehfar H, Meyer C, Ezziddin S, Sabet A, Hoff-Meyer A, Muckle M, et al. Hepatic volume changes induced by radioembolization with $90 \mathrm{Y}$ resin microspheres. A single-centre study. Eur J Nucl Med Mol Imaging. 2013;1:80-90.

11. Garlipp B, de Baere T, Damm R, Irmscher R, van Buskirk M, Stübs $\mathrm{P}$, et al. Left-liver hypertrophy after therapeutic right-liver radioembolization is substantial but less than after portal vein embolization. Hepatology. 2014;5:1864-73.

12. Edeline J, Lenoir L, Boudjema K, Rolland Y, Boulic A, Le Du F, et al. Volumetric changes after (90)y radioembolization for hepatocellular carcinoma in cirrhosis: an option to portal vein embolization in a preoperative setting? Ann Surg Oncol. 2013;8:2518-25.

13. Vouche M, Lewandowski RJ, Atassi R, Memon K, Gates VL, Ryu RK, et al. Radiation lobectomy: time-dependent analysis of future liver remnant volume in unresectable liver cancer as a bridge to resection. Hepatology. 2013;5:1029-36.

14. Aoki T, Kubota K. Preoperative portal vein embolization for hepatocellular carcinoma: Consensus and controversy. World J Hepatol. 2016;9:439-45.

15. Theysohn JM, Ertle J, Müller S, Schlaak JF, Nensa F, Sipilae S, et al. Hepatic volume changes after lobar selective internal radiation therapy (SIRT) of hepatocellular carcinoma. Clin Radiol. 2014;2: $172-8$.

16. Fernández-Ros N, Silva N, Bilbao JI, Iñarrairaegui M, Benito A, D'Avola D, et al. Partial liver volume radioembolization induces hypertrophy in the spared hemiliver and no major signs of portal hypertension. HPB (Oxford). 2014;3:243-9.

17. Carpizo DR, Gensure RH, Yu X, Gendel VM, Greene SJ, Moore $\mathrm{DF}$, et al. Pilot study of angiogenic response to yttrium-90 radioembolization with resin microspheres. J Vasc Interv Radiol. 2014:2:297-306.

18. Fernandez-Ros N, Iñarrairaegui $M$, Paramo JA, Berasain C, Avila MA, Chopitea A, et al. Radioembolization of hepatocellular carcinoma activates liver regeneration, induces inflammation and endothelial stress and activates coagulation. Liver Int. 2015;5:1590-6.

19. Lewandowski RJ, Andreoli JM, Hickey R, Kallini JR, Gabr A, Baker T, et al. Angiogenic Response following Radioembolization: Results from a Randomized Pilot Study of Yttrium-90 with or without Sorafenib. J Vasc Interv Radiol. 2016;9:1329-36.

20. Seidensticker M, Powerski M, Seidensticker R, Damm R, Mohnike $\mathrm{K}$, Garlipp B, et al. Cytokines and 90Y-Radioembolization: Relation to Liver Function and Overall Survival. Cardiovasc Intervent Radiol. 2017;8:1185-95.

21. Chiesa C, Maccauro M, Romito R, et al. Need, feasibility and convenience of dosimetric treatment planning in liver selective internal radiation therapy with $90 \mathrm{Y}$ microspheres: the experience of the National Tumor Institute of Milan. Q J Nucl Med Mol Imaging. 2011;52:168-97.

22. Garin E, Lenoir L, Rolland Y, Edeline J, Mesba H, Laffont S, et al. ${ }^{99 m}$ Tc-MAA SPECT/CT based dosimetry accurately predicts tumour response and survival in $\mathrm{HCC}$ patients treated with ${ }^{90} \mathrm{Y}$-loaded glass microspheres : preliminary results. J Nucl Med. 2012;2: 255-63.

23. Garin E, Rolland Y, Pracht M, Le Sourd S, Laffont S, Mesbah H, et al. High impact of macroaggregated albumin-based tumour dose on response and overall survival in hepatocellular carcinoma patients treated with ${ }^{90} \mathrm{Y}$-loaded glass microsphere radioembolization. Liver Int. 2017;1:101-10.

24. Chiesa C, Mira M, Maccauro M, Spreafico C, Romito R, Morosi C, et al. Radioembolization of hepatocarcinoma with (90)Y glass microspheres: development of an individualized treatment planning strategy based on dosimetry and radiobiology. Eur J Nucl Med Mol Imaging. 2015;11:1718-38.

25. Garin E, Lenoir L, Edeline J, Laffont S, Mesbah H, Porée P, et al. Boosted selective internal radiation therapy with ${ }^{90} \mathrm{Y}$-loaded glass microspheres (B-SIRT) for hepatocellular carcinoma patients: a new personalized promising concept. Eur J Nucl Med Mol Imaging. 2013;7:1057-68.

26. Avila MA, Moschetta A. The FXR-FGF19 Gut-Liver Axis as a Novel "Hepatostat". Gastroenterology. 2015;149:537-40.

27. Michalopoulos GK. Hepatostat: Liver regeneration and normal liver tissue maintenance. Hepatology. 2017;4:1384-92.

28. Webber EM, Bruix J, Pierce RH, Fausto N. Tumor necrosis factor primes hepatocytes for DNA replication in the rat. Hepatology. 1998;28:1226-34

29. Sérandour AL, Loyer P, Garnier D, Courselaud B, Théret N, Glaise $\mathrm{D}$, et al. TNFalpha-mediated extracellular matrix remodeling is required for multiple division cycles in rat hepatocytes. Hepatology. 2005;3:478-86

30. Fausto N, Campbell JS, Riehle KJ. Liver regeneration. Hepatology. 2006;43:S45-53.

31. Nalesnik MA, Federle M, Buck D, Fontes P, Carr BI. Hepatobiliary effects of 90yttrium microsphere therapy for unresectable hepatocellular carcinoma. Hum Pathol. 2009;1:125-34.

32. Denys A, Prior J, Bize P, Duran R, De Baere T, Halkic N, et al. Portal vein embolization: what do we know? Cardiovase Intervent Radiol. 2012;5:999-1008.

33. Braat MNGJA, de Jong HW, Seinstra BA, Scholten MV, van den Bosch MAAJ, Lam MGEH. Hepatobiliary scintigraphy may improve radioembolization treatment planning in HCC patients. EJNMMI Res. 2017;1:2. 